\title{
POLÍTICAS PÚBLICAS PARA O ESPORTE: O PROGRAMA BOLSA- ATLETA E SUA ABRANGÊNCIA NA BASE DO HANDEBOL NO BRASIL $^{1}$
}

\author{
Philipe Rocha de Camargo \\ Universidade Federal do Paraná, Curitiba, Paraná, Brasil \\ Fernando Marinho Mezzadri \\ Universidade Federal do Paraná, Curitiba, Paraná, Brasil
}

\begin{abstract}
Resumo
O objetivo desse estudo incidiu em identificar a abrangência do programa Bolsa-Atleta na formação de atletas do handebol brasileiro entre 2008 e 2014. Essa pesquisa, de caráter documental e abordagem teórica em Políticas Públicas, utilizou fontes oficiais do Governo, com suporte do Programa Inteligência Esportiva da Universidade Federal do Paraná (UFPR)/Ministério do Esporte e as listas de contemplados no Programa Bolsa-Atleta, divulgadas no site do Ministério do Esporte e devidamente publicadas no Diário Oficial da União. Concluiu-se que há investimento priorizado nas categorias de bolsa de maior valor; o programa Bolsa-Atleta não assegura investimento na formação de atletas no handebol, pois as categorias de bolsa Base e Estudantil não alcançaram 5\% dos atletas da modalidade.
\end{abstract}

Palavras-chave: Handebol. Bolsa-Atleta. Política Pública. Esporte.

\section{Introdução}

As políticas públicas como área de conhecimento no Brasil é um fenômeno ainda recente. Souza (2006) afirma que a Política Pública foi introduzida como uma ferramenta de decisões governamentais nos Estados Unidos na década de 1940, uma década antes disso, porém, o sociólogo Harold Dwight Lasswell já haveria introduzido a expressão "policy analysis" - Análise de políticas públicas - "como forma de conciliar conhecimento científico/acadêmico com a produção empírica dos governos e também como forma de estabelecer o diálogo entre cientistas sociais, grupos de interesse e governo" (SOUZA, 2006 p. 23). A autora considera ainda a prerrogativa da política pública como campo de conhecimento que busca colocar o governo em ação, avaliar tal ação e, se necessário, propor mudanças no rumo dessas ações.

Frey (2000, p. 214) reitera que o interesse da Política Pública como área de conhecimento não se restringe a aumentar o conhecimento sobre planos, programas e projetos desenvolvidos e implementados pelos governos como políticas setoriais. Segundo o autor, a pesquisa em política pública pretende analisar a inter-relação entre as instituições políticas, os conteúdos políticos e os processos decisórios da política, de maneira a possibilitar o desenvolvimento de um arcabouço de questionamentos respaldados pela ciência política.

No que se referem aos estudos a respeito das políticas públicas para o esporte, para autores como Shilbury, Sotiriadou e Green (2008), Houlihan e Green (2008), De Bosscher et al.

\footnotetext{
${ }^{1}$ O presente trabalho contou com o apoio financeiro da Coordenação de Aperfeiçoamento de Pessoal de Nível Superior (CAPES).
} 
(2009), Houlihan e Zheng (2013) já está evidenciado um aumento crescente nos casos de intervenção do Estado nos assuntos esportivos por meio de políticas públicas para a área. Isso é fundamentalmente mais expressivo no que se refere ao financiamento esportivo com o objetivo de estimular o desenvolvimento do esporte de rendimento no país. Contudo, para tais estudiosos das políticas públicas para o esporte, parece ainda não estar totalmente evidente até que ponto o envolvimento entre as políticas públicas e o esporte de rendimento pode proporcionar benefícios pontuais a uma sociedade.

Baseados pelo entendimento científico da política pública, e ao observarmos as assertivas apresentadas à luz do contexto atual do esporte no país - de realização de megaeventos esportivos - nos permite deduzir essa como a ocasião oportuna para estudar as políticas para o esporte que estão sendo executadas com o objetivo de estimular o momento esportivo do país; tal qual o presente trabalho se propõe: analisar o Programa Bolsa-Atleta (Lei $\mathrm{n}^{\circ} 10.891$, de 09 de julho de 2004) e seu alcance na base do handebol brasileiro.

De modo a facilitar a compreensão acerca da política do programa Bolsa-Atleta e sua inserção no cenário nacional, convém destacar que, apesar de ter sido instituído apenas em 2004, o programa fora elaborado no fim de 2000 após a frustração esportiva do país nos Jogos Olímpicos de Sidney (2000). Naquele cenário, a partir de discussões sobre as dificuldades vividas pelos atletas em conseguir patrocínios, o programa surgia como uma maneira de estimular e subsidiar a preparação olímpica do país, através do benefício direto aos atletas (GUIMARÃES, 2009).

O programa de concessão de bolsas visa garantir condições mínimas para que os atletas se dediquem com exclusividade aos treinamentos e às competições, e, consequentemente, mantenham os níveis competitivos. Em 2011, a partir da escolha do Brasil como país sede dos Jogos Olímpicos de 2016, uma nova legislação é promulgada (Lei ${ }^{\circ}$ 12,395/2011 ${ }^{2}$ ) trazendo, dentre todas as modificações, a inclusão de uma nova categoria de bolsa (Bolsa Pódio) com finalidade exclusiva de impulsionar a preparação olímpica do país. Atualmente, o programa possui seis categorias de bolsas - Base, Estudantil, Nacional, Internacional, Olímpica/Paralímpica e Pódio ${ }^{3}$ - e é válido por um período de até 12 meses, renovável anualmente desde que os atletas continuem atingindo os critérios estabelecidos.

Apesar de ser uma política recente, o programa Bolsa-Atleta é fundamental para o avanço do esporte no Brasil. Isso se dá pelo fato de ser uma ação direcionada exclusivamente ao atleta sem que os recursos passem pelas instituições que organizam e controlam a modalidade (CORRÊA et al., 2014; CAMARGO, 2016; CORRÊA, 2016). Outrossim, quando observada a cobertura do programa e sua relação com as modalidades menos favorecidas por apoio financeiro provenientes de patrocinadores, Reis et al. (2015) reforçam que o programa, a partir do direcionamento de recursos diretos aos atletas, se caracteriza como uma das principais fontes de renda dos atletas de modalidades sem patrocinadores.

É função das Confederações indicar as competições nacionais e/ou internacionais que serão válidas como requisitos para a inscrição dos atletas no programa e, por fim, confirmar a participação destes na competição indicada. Todavia, apesar de ser um benefício direto aos atletas, a participação de sua respectiva Confederação esportiva é essencial nesse processo. Nesse sentido, a compreensão dessa autonomia de indicação que é dada às Confederações é recebida de maneira crítica por parte de alguns pesquisadores das políticas para o esporte. Isso se deve ao fato de que tal autonomia poderia pressupor a utilização estratégica desse critério

\footnotetext{
${ }^{2}$ Em 16 de março de 2011 foi promulgada a Lei ${ }^{\circ}$ 12,395, lançando o Plano Brasil Medalhas, e inserindo uma nova modalidade de bolsa, a bolsa pódio para atletas de modalidades olímpicas individuais que estejam entre os 20 melhores do ranking mundial e que possuam condições de conquista de medalhas nas Olimpíadas do Rio em 2016: http://brasil2016.gov.br/pt-br/olimpiadas/investimentos/bolsa-atleta-podio.

${ }^{3} \mathrm{O}$ site do ME informa os critérios para a participação no programa. Disponível em:< http://www2.esporte.gov.br/snear/bolsaAtleta/prerequisitos.jsp>.
} 
para favorecer determinadas Federações esportivas, modalidades e, sobretudo, atletas (CAMARGO, 2016; CORRÊA, 2016).

Convém ressaltar que, embora tenha demonstrado adquirir uma abrangência e aceitação de grande magnitude no âmbito esportivo, no universo científico-acadêmico, autores têm destacado a insuficiência de critérios de controle e fiscalização do Bolsa Atleta, bem como fragilidades no processo de democratização e abrangência das oportunidades em receber os benefícios dessa política (TEIXEIRA; MATIAS; MASCARENHAS, 2013). Silva et al.(2015) corroboram com a percepção dessas fragilidades, ao destacarem que o programa impõe critérios de concessão de bolsas sem levar em consideração os métodos de avaliação dos resultados alcançados pelos atletas e pela própria política. Para os autores, apesar de se tratar de uma iniciativa notável, a inexistência de avaliação pode pressupor a ausência de benefícios - como se propõe - caracterizando a ação apenas como estratégia de investimento no esporte.

Para outros autores (SANTOS; COSTA; SILVA, 2012; MAZZEI et al, 2012), as políticas para o esporte, que têm sido implantadas com a finalidade de colocar o Brasil entre as principais potências esportivas mundiais, estão sendo desenvolvidas a partir de aspectos emergenciais, sem um planejamento de longo prazo e, sobretudo, sobre a premissa de atender as urgências de um evento olímpico que será realizado no Brasil. Para esses autores, em contraposição do que foi proposto por outros países também anfitriões dos Jogos Olímpicos, o Brasil tem se comprometido a impulsionar a preparação olímpica a partir de atletas que já figuram no topo de suas modalidades, quando, na verdade, deveria estar direcionando o investimento no fomento e na formação de base do esporte nacional, bem como na detecção de novos talentos esportivos. Essa estratégia poderia dificultar o alcance do sucesso esportivo e tornar os resultados dos projetos existentes pouco duradouros.

A partir dos esclarecimentos anteriores e do entendimento de como tem se configurado o programa Bolsa-Atleta como uma política para o desenvolvimento do esporte, mas acima de tudo como uma oportunidade para as modalidades menos privilegiadas (cultural, midiática e/ou financeiramente) no cenário esportivo nacional, pretende-se nessa pesquisa analisar o programa Bolsa-Atleta do Governo Federal em associação com a Confederação Brasileira de Handebol ( $\mathrm{CBHb})$, especialmente no que se refere aos dados de como têm sido distribuídas as bolsas desta modalidade.

Para tanto, observando as ações das seleções de base masculina e feminina de handebol (para atletas de até 18 anos e 20 anos, respectivamente), bem como as bolsas disponibilizadas relativas a tais faixas etárias (Bolsa Base, que beneficia atletas de até 19 anos, e Bolsa Estudantil, para atletas de até 20 anos), e entendendo que tais seleções, nessas faixas etárias, representam a detecção e a formação de atletas para as modalidades, em especial no handebol, esse trabalho buscará responder: qual a abrangência do programa Bolsa-Atleta na formação de atletas do handebol brasileiro?

De modo que seja possível chegarmos à elucidação de tal questionamento, teremos como objetivos específicos: A) Identificar e quantificar os atletas de base que integraram a Seleção Juvenil e/ou Junior, masculina e feminina de handebol no período entre 2008 e 2014; B) Identificar se esses atletas são e/ou foram contemplados pelo programa Bolsa-Atleta e em quais categorias de bolsa.

\section{Metodologia}

Esse trabalho segue uma estratégia de pesquisa em nível exploratório e de cunho documental, e sequencialmente pode ser caracterizado como pesquisa quanti-qualitativa (LAKATOS; MARCONI, 1991). 
De maneira a sedimentar o referencial teórico a respeito das políticas públicas, e com mais especificidade, das políticas públicas para o esporte, nos apropriamos dos documentos de Frey (2000) e Souza (2006).

As fontes de coleta de dados desse estudo foram: a) Banco de dados do Programa Inteligência Esportiva UFPR/Ministério do Esporte, onde estão cadastrados e caracterizados os atletas beneficiados pelo programa Bolsa-Atleta de acordo com as listas divulgadas no Diário Oficial da União ${ }^{4}$; b) Documentos oficiais do governo brasileiro relativos ao programa BolsaAtleta - listas de atletas contemplados divulgadas no site do Ministério do Esporte e devidamente publicadas no "Diário Oficial da União"5; e de maneira a contribuir para o enriquecimento dos dados, e consequentemente do assunto, c) Informações disponibilizadas pela Federação Internacional de Handebol (IHF) ${ }^{6}$, Comitê Olímpico Internacional (COI), Confederação Brasileira de Handebol (CBHb), Ministério do Esporte (ME) e/ou outros órgãos oficiais do Estado Brasileiro, através de sites, artigos em revistas, jornais e/ou páginas digitais de notícias.

Essa pesquisa abrangeu o período entre 2008 e 2014, o mesmo período em que no Banco de Dados do Programa Inteligência Esportiva UFPR/Ministério do Esporte já estão catalogados os atletas beneficiários do programa Bolsa-Atleta do Governo Federal.

No que tange as categorias de bolsas utilizadas como referência de análise no processo de formação de atletas, ainda que sejam prioritárias, segundo o escopo da pesquisa (equipes de base), as categorias Bolsa Base e Bolsa Estudantil, serão utilizadas todas as categorias existentes no programa de maneira a fundamentar indagações e/ou hipóteses.

Entendemos, para tanto, que as ditas categorias de base compreendem o período que se inicia a partir dos 14 anos de idade, em que o jovem atleta dá início ao processo de aperfeiçoamento e especialização das técnicas esportivas e se prolonga até o período entre os 18 e 21 anos, idade que compreende o marco de transição em que o mesmo já tem projetada sua possibilidade de êxito no esporte de alto nível (BARBANTI, 1979; MALINA; BOUCHARD, 1991; MATTA; GRECO 1996; MARTIN, 1988 apud BOHME, 2000, p. 5).

\section{Resultados e discussão}

De maneira a compreender a existência de uma possível evolução das seleções brasileiras de handebol de base, pesquisamos e elencamos as competições e as respectivas classificações de cada seleção nos eventos que as mesmas participaram, conforme Tabelas 1 e 2 .

É possível observar na Tabela 1 a ascensão na classificação da equipe Junior masculina, tanto nos Jogos Pan-Americanos, quanto no Campeonato Mundial, fato não repetido pela equipe Junior feminina. A equipe Junior feminina apresenta melhoria no desempenho apenas nas edições dos Jogos Pan-Americanos, sendo observado um declínio nos resultados das edições do Campeonato Mundial.

\footnotetext{
${ }^{4}$ As listagens de atletas contemplados estão disponíveis para consulta no seguinte link, disponível em:< http://www2.esporte.gov.br/snear/bolsaAtleta/listaContemplados.jsp>.

${ }^{5}$ Idem.

${ }^{6}$ Resultados das últimas edições do Campeonato Mundial e/ou Jogos Olímpicos, disponíveis na aba das competições, e no link de estatística (masculina e/ou feminina) do site da IHF, disponível em:< http://www.ihf.info>.
} 
Tabela 1 - Classificação por competição das Seleções Brasileira Masculina e Feminina Junior de Handebol.

\begin{tabular}{|c|c|c|c|c|}
\hline \multicolumn{5}{|c|}{ Posições das Seleções Brasileiras Junior de Handebol } \\
\hline & \multicolumn{2}{|c|}{ Seleção Masculina } & \multicolumn{2}{|c|}{ Seleção Feminina } \\
\hline Ano & $\begin{array}{c}\text { Campeonato Mun- } \\
\text { dial Junior }\end{array}$ & $\begin{array}{c}\text { Jogos Pan- } \\
\text { Americanos }\end{array}$ & $\begin{array}{c}\text { Campeonato Mun- } \\
\text { dial Junior }\end{array}$ & $\begin{array}{l}\text { Jogos Pan- } \\
\text { Americanos }\end{array}$ \\
\hline 2008 & & & Oitavas $-9^{\circ}$ & Fase Final $-2^{\circ}$ \\
\hline 2009 & Oitavas $-9^{\circ}$ & Fase Final $-2^{\circ}$ & & \\
\hline 2010 & & & Fase de grupos $-12^{\circ}$ & Fase Final $-2^{\circ}$ \\
\hline 2011 & Oitavas $-11^{\circ}$ & Fase Final $-2^{\circ}$ & & \\
\hline 2012 & & & Oitavas $-12^{\circ}$ & Fase Final $-1^{\circ}$ \\
\hline 2013 & Quartas $-6^{\circ}$ & Fase Final $-1^{\circ}$ & & \\
\hline 2014 & & & Oitavas $-15^{\circ}$ & Fase Final $-1^{\mathrm{a}}$ \\
\hline
\end{tabular}

Fonte: Dados da Federação Internacional de Handebol - IHF e da Confederação Brasileira de Handebol - $\mathrm{CBHb}$.

No que se referem às equipes masculina e feminina Juvenil (Tabela 2), em ambas é possível observar uma melhoria de suas classificações nas edições dos Jogos Pan-Americanos e do Campeonato Mundial, entretanto, quando analisados os resultados relativos aos Jogos Olímpicos da Juventude, observamos que as duas equipes perderam uma posição na classificação final quando comparadas às duas edições realizadas. O Brasil manteve a hegemonia continental, e isso se tornou visível nos resultados alcançados pela seleção masculina e feminina Juvenil, que se mantiveram entre a primeira e a segunda colocação.

\section{Tabela 2 - Classificação por competição das Seleções Brasileira Masculina e Feminina Juvenil de Handebol.}

\begin{tabular}{|c|c|c|c|c|c|c|}
\hline \multicolumn{7}{|c|}{ Posições das Seleções Brasileiras Juvenis de Handebol } \\
\hline & \multicolumn{3}{|c|}{ Seleção Masculina } & \multicolumn{3}{|c|}{ Seleção Feminina } \\
\hline Ano & $\begin{array}{c}\text { Campeonato } \\
\text { Mundial Juve- } \\
\text { nil }\end{array}$ & $\begin{array}{l}\text { Jogos Pan- } \\
\text { Americanos }\end{array}$ & $\begin{array}{c}\text { Jogos Olímpi- } \\
\text { cos da Juven- } \\
\text { tude }\end{array}$ & $\begin{array}{c}\text { Campeonato } \\
\text { Mundial Juvenil }\end{array}$ & $\begin{array}{l}\text { Jogos Pan- } \\
\text { Americanos }\end{array}$ & $\begin{array}{l}\text { Jogos Olímpicos } \\
\text { da Juventude }\end{array}$ \\
\hline 2008 & & Fase Final $-2^{\circ}$ & & Oitavas $-10^{\circ}$ & Fase Final $-1^{\circ}$ & \\
\hline 2009 & Oitavas $-15^{\circ}$ & & & & & \\
\hline 2010 & & Fase Final $-1^{\circ}$ & Fase Final $-4^{\circ}$ & Oitavas $-7^{\circ}$ & Fase Final $-1^{\circ}$ & Fase Final $-3^{\circ}$ \\
\hline 2011 & Oitavas $-12^{\circ}$ & Fase Final $-2^{\circ}$ & & & & \\
\hline 2012 & & & & $\begin{array}{l}\text { Fase de Grupos - } \\
12^{\circ}\end{array}$ & Fase Final $-1^{\circ}$ & \\
\hline 2013 & Oitavas $-9^{\circ}$ & Fase Final $-2^{\circ}$ & & & & \\
\hline 2014 & & Fase Final $-1^{\circ}$ & $\begin{array}{l}\text { Fase de Grupos } \\
-5^{\circ}\end{array}$ & Oitavas $-7^{\circ}$ & Fase Final $-1^{\mathrm{a}}$ & Fase Final $-4^{\circ}$ \\
\hline
\end{tabular}

Fonte: Dados da Federação Internacional de Handebol - IHF e da Confederação Brasileira de Handebol $-\mathrm{CBHb}$

Ao levantarmos as informações referentes às competições disputadas pelas seleções de base, identificamos, por meio das listas de convocações, um total de 242 atletas integrantes das equipes Junior e Juvenil em ambos os sexos no período entre 2008 e 2014. O rodízio de atletas, que compuseram as equipes Junior e Juvenil femininas, foi maior do que pelas equipes Junior e Juvenil masculinas. Foram contabilizados 114 atletas pela equipe masculina e 128 
pela equipe feminina. Apesar de ter apresentado um número maior no quantitativo total de atletas convocadas para as seleções no período, das 128 atletas, 40 delas foram convocadas em ambas as categorias, Junior e Juvenil (31\%). No que se refere à equipe masculina, 29 atletas estiveram na mesma situação, sendo convocados a participar em ambas as categorias, 0 que correspondeu a $25 \%$ dos 114 atletas que integraram a equipe no período.

Do total de 242 atletas em ambos os sexos, 181 atletas foram beneficiados por alguma categoria de bolsa no programa no período, o que corresponde a $75 \%$ de todos os integrantes das seleções de base. Um valor de referência substancialmente alto, quando comparado ao total de 840 bolsistas catalogados no Banco de Dados do Programa Inteligência Esportiva UFPR/Ministério do Esporte, conferido pelas listas disponibilizadas pelo site do Ministério do Esporte e que foram divulgadas no Diário Oficial da União, contemplado até dezembro de 2015.

Mais especificamente, esse dado nos permite inferir que os atletas bolsistas que compuseram as seleções Junior e Juvenil no período entre 2008 e 2014 são responsáveis por 22\% de todas as bolsas disponibilizadas desde a instituição do programa Bolsa-Atleta, até o momento. Ao todo foram concedidas 431 bolsas aos integrantes das seleções de base no período, divididas do seguinte modo: 10 bolsas na categoria Olímpica, 221 na categoria Internacional, 183 na categoria Nacional, 15 bolsas na categoria Base e apenas duas na categoria Estudantil.

Esses valores, racionados entre os gêneros, estão demonstrados abaixo, no Gráfico 1. Tais levantamentos reforçam a magnitude da abrangência do programa Bolsa-Atleta quando nos referimos ao alto rendimento da modalidade no cenário nacional, mas, sobretudo, acerca da capacidade e cobertura do benefício aos atletas que representam o país nas competições Internacionais.

\section{Gráfico 1 - Demonstrativo de Bolsas concedidas por categoria e gênero na Seleção Brasi- leira Juvenil e Junior de Handebol.}

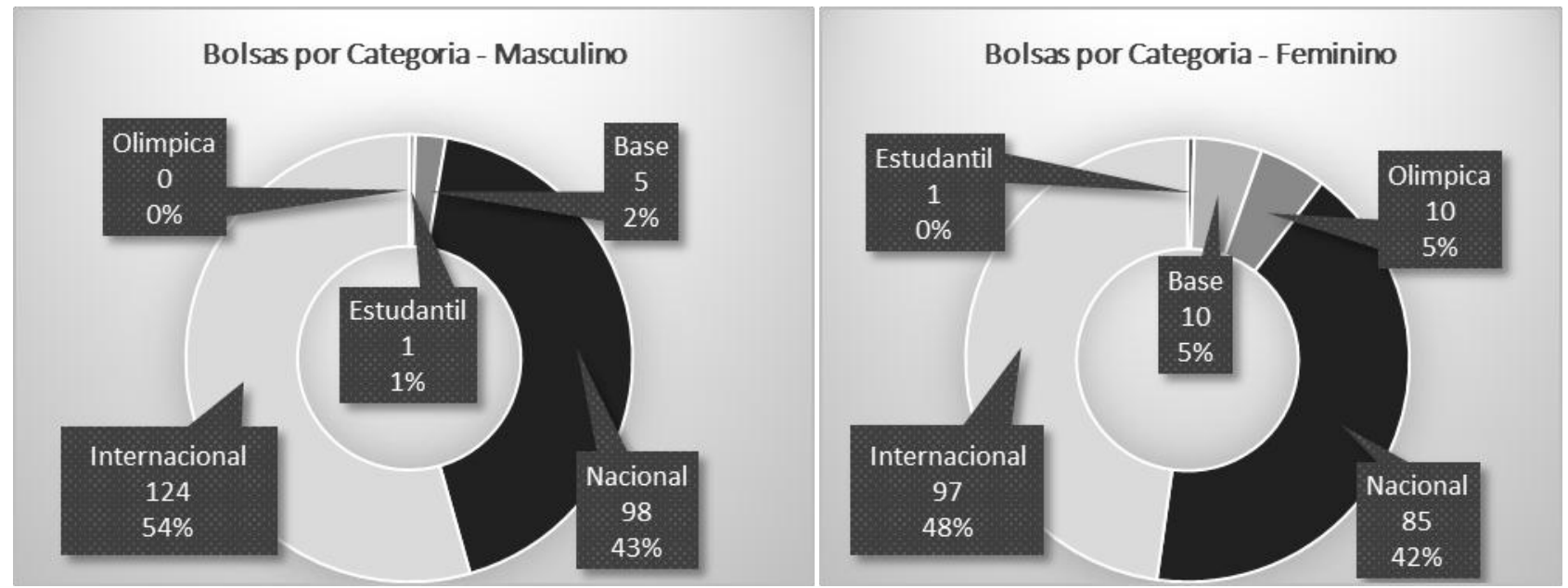

Fonte: Elaborado pelos autores

É possível observar que a presença da bolsa na categoria Internacional foi ainda maior na equipe masculina do que na feminina, $55 \%$ e $48 \%$, respectivamente. Entretanto, é possível também notar que a categoria de bolsa Olímpica só esteve presente na equipe feminina, $5 \%$ de todas as bolsas. Isso aconteceu pelo fato de que, em 2012, a equipe masculina não conseguiu se classificar para os Jogos Olímpicos de Londres, o que impossibilitou que os atletas solicitassem o benefício. 
Ressaltamos, também, a presença de apenas duas bolsas na categoria Estudantil, sendo uma pelo masculino e uma pelo grupo feminino, bem como 15 bolsas na categoria Base - dessas, 10 no feminino e cinco no masculino. De acordo com os dados obtidos, foi possível constatar que os dois atletas beneficiados pela bolsa na categoria Estudantil estão entre os 15 atletas que foram beneficiados pela categoria Bolsa Base no mesmo período entre 2008 e 2014.

Esses dados merecem atenção, já que o presente trabalho se concentra na investigação das políticas públicas voltadas às categorias de base do handebol no país, e é observado apenas duas bolsas Estudantis e 15 de Base no período (2008 a 2014). Esses números representam um percentual inferior a $5 \%$ do total de bolsas concedidas e direcionadas às categorias de base da modalidade. As categorias Base e Estudantil representaram 4\% e 0,49\%, respectivamente, do total de bolsas concedidas aos atletas de handebol no período investigado (Gráfico 2).

\section{Gráfico 2. Demonstrativo percentual de cada categoria de bolsa no período entre 2008 e} 2014.

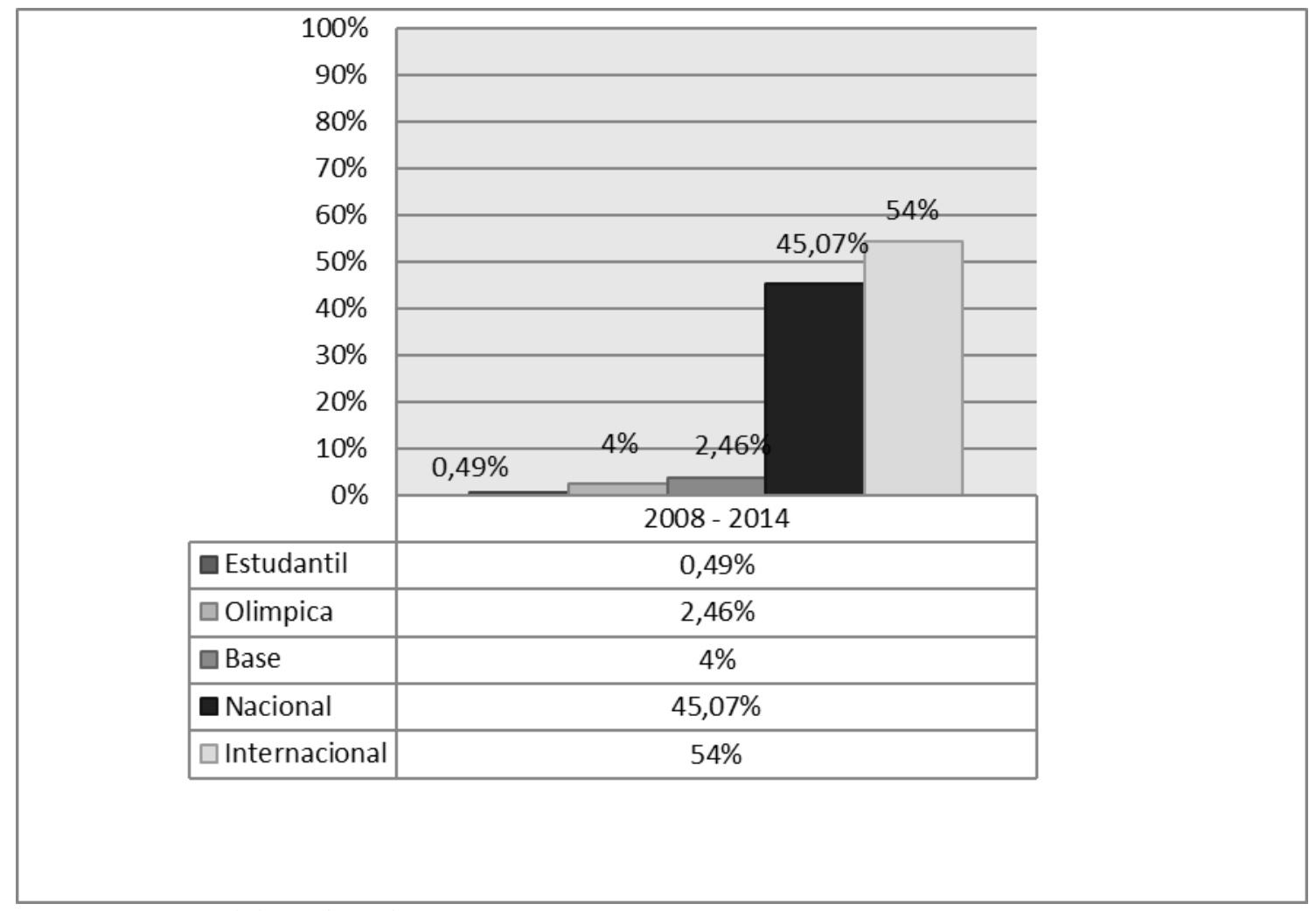

Fonte: elaborado pelos autores

Ao entendermos, fundamentados em autores como Bohme $(2007 ; 2013)$ que o desenvolvimento das categorias de base é fundamental no processo de formação de novos atletas e que contribuem diretamente para que esse desenvolvimento aconteça, fica evidente a fragilidade do programa quanto à sua efetividade no fomento às categorias de base. Os estudos realizados por De Bosscher et al. $(2007 ; 2009 ; 2010 ; 2013)$ corroboram com essa assertiva ao caracterizarem a "Participação e esporte de base", e "Identificação de talentos e Sistema de Desenvolvimento" como dois pilares fundamentais para o sucesso esportivo internacional de uma modalidade.

Em contraposição ao que deveria estar sendo desenvolvido pelo programa, de acordo com o Gráfico 2, é possível observar que a categoria de bolsa de maior presença no programa 
Bolsa-Atleta nas seleções de base, no período de análise, foi a categoria Internacional que correspondeu a 54\% do total de bolsas concedidas, seguida pela categoria Nacional que somou 45,07\%. A categoria Olímpica apresentou menos de 2,5\%, e, como ressaltado anteriormente, as categorias de base (Base e Estudantil) obtiveram um percentual inferior a 5\%, somadas ambas as categorias.

Convém destacar que o caráter imediatista do programa aparenta estar presente desde sua gênese em 2004. Isso pode ser verificado na sua proposta inicial, que não contemplava o benefício aos atletas das categorias de base. A categoria Bolsa Base surgiu apenas a partir da modificação do programa pela Lei 12.395/2011. Isso poderia pressupor que, já na sua implantação, o benefício previa beneficiar os atletas que já se apresentavam no topo do esporte de rendimento do país, e, consequentemente, não se apresentava como plano de desenvolvimento de novos talentos.

Frey (2000) observa a existência de uma interdependência entre os processos e os reais resultados das propostas políticas, já que os atores do corpo político, bem como seus interesses e os interesses dos diversos grupos da sociedade, podem condicionar modificações ao longo do processo decisório. Isso pode ser observado nas alterações do projeto que instituiu o programa Bolsa-Atleta.

Embora as modificações no programa Bolsa-Atleta tenham proporcionado a criação de uma categoria que beneficiasse diretamente as categorias de base, a nova proposta de bonificação de atletas confirmava o indício de preocupação com os problemas imediatos do esporte brasileiro. Em meio à euforia causada pela eleição do Brasil como sede dos Jogos Olímpicos de 2016 - em outubro de 2009 -, e pela necessidade de impulsionar a preparação do país para o evento, a Lei $n^{\circ}$ 12.395/2011, que ficou conhecida como Plano Brasil Medalhas (PBM), injetou um montante de um bilhão de reais ao esporte brasileiro. Desse total, um terço seria destinado à preparação de atletas de modalidades olímpicas/paralímpicas individuais, que tivessem possibilidade de conquistar medalhas nos jogos e que estivessem entre os 20 melhores do ranking internacional de sua modalidade, por meio de uma nova categoria de bolsa, a Bolsa Pódio ${ }^{7}$ (BRASIL, 2011). Tal situação ilustra, como mencionado por Souza (2006), que para a política pública, essas alterações nas legislações vigentes se tratam de incrementos e alternativas encontradas pela consciência coletiva, com o objetivo de enfrentar um problema e se adaptar às necessidades do momento.

Os dados apresentados no Gráfico 3 sustentam o enunciado anteposto, e confirmam a manutenção da omissão às categorias de base da modalidade, pelo menos no que diz respeito ao financiamento de bolsas a atletas. Ainda que em 2011, ano de sua implantação, a categoria tenha demonstrado sua maior expressividade, chegando a cerca de $11 \%$, nos demais anos sua representatividade é insignificante ou inexistente.

\footnotetext{
${ }^{7}$ Informações disponíveis no site do Ministério do Esporte, em:< http://www.esporte.gov.br/index.php/institucional/alto-rendimento/plano-brasil-medalhas>.
} 
Gráfico 3. Histórico percentual anual de Bolsas por categorias.

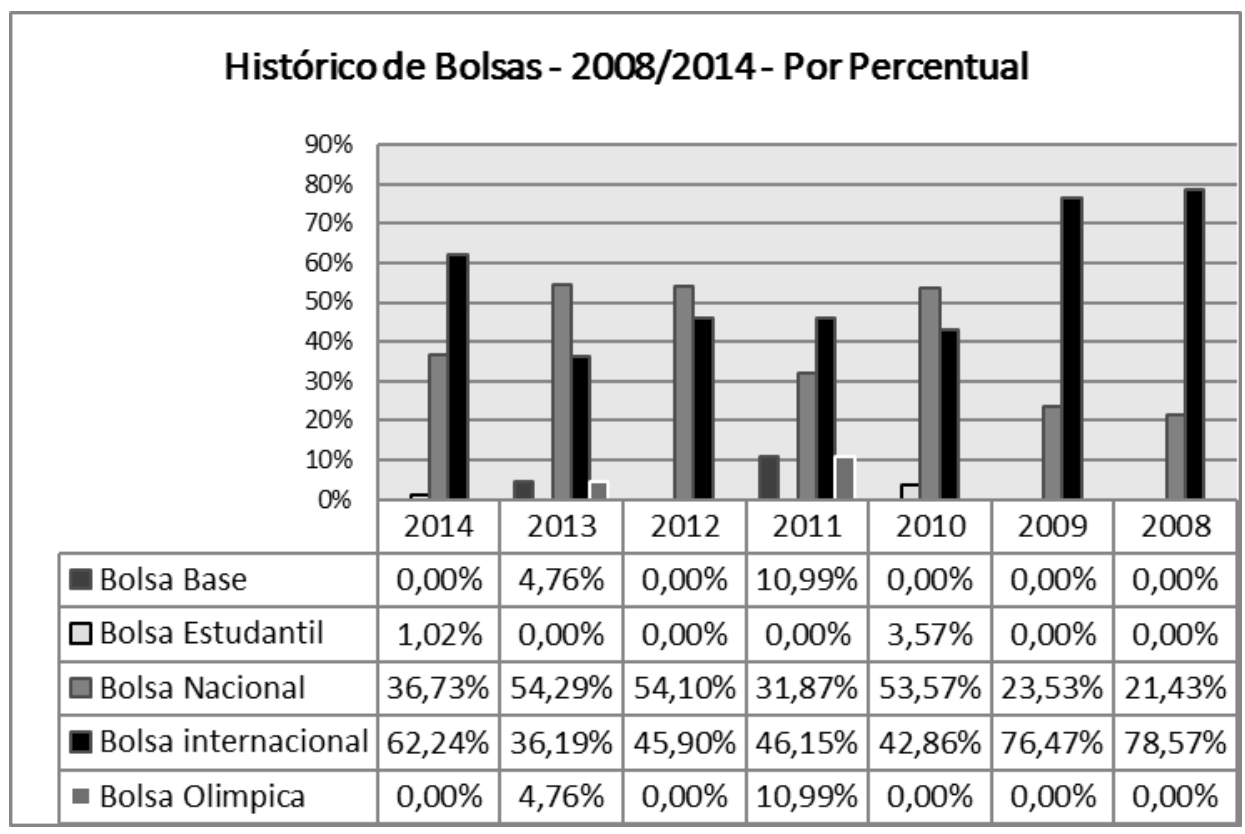

Fonte: elaborado pelos autores.

Buscamos, a partir dos documentos levantados, informações que nos possibilitassem determinar se, dentre os 15 atletas beneficiados pelas bolsas relativas às categorias de base (Bolsa Base e Bolsa Estudantil), quantos haviam sido beneficiados por outros tipos de bolsas. Identificamos que apenas dois atletas receberam uma única bolsa, sendo esta a Bolsa Base. Todos os 13 restantes foram beneficiados por duas ou mais bolsas no período, sendo $40 \%$ beneficiados por duas bolsas, $26,67 \%$ por três bolsas e $20 \%$ por quatro bolsas, considerando o período entre 2008 e 2014.

De acordo com a análise dos dados, constatou-se que, dentre esses 15 atletas beneficiados pelas Bolsas nas categorias de base, $11(74 \%)$ foram também beneficiados pela bolsa na categoria Nacional e 10 (67\%) pela bolsa na categoria Internacional. Desse universo, $40 \%$ dos atletas apresentaram o que podemos considerar como uma escala de evolução e foram beneficiados com bolsa Nacional após receberem as bolsas Base ou Estudantil, enquanto outros $33 \%$ pularam da categoria Base direto para a categoria Internacional. Por outro lado, uma minoria $(13,33 \%)$ apresentou uma ordem inversa no benefício, tendo recebido inicialmente a bolsa Nacional e nos anos seguintes foram beneficiados pela categoria Base.

Para alguns pesquisadores das ciências dos esportes, como Santos, Costa e Silva (2012) e Mazzei et al. (2012), a solução encontrada pelo Governo por meio das políticas para o esporte, como o Bolsa-Atleta, assemelha-se a um plano pontual e emergencial, já que para os autores, os gestores de tal processo omitiram a necessidade da consolidação de métodos a longo prazo que respeitem as previsões das ferramentas necessárias e que influenciam diretamente no desenvolvimento do atleta e, consequentemente, do seu rendimento. Para os autores, ao contrário de grandes potências olímpicas que se planejaram e se organizaram para financiar e estimular o desenvolvimento do esporte, em média, por 12 anos (três ciclos olímpicos), o Brasil, equivocadamente, se mobilizou a fazê-lo em um período de quatro anos, dessa forma, arriscando-se a não obter o sucesso esperado no evento (SANTOS; COSTA; SILVA, 2012). 
A crítica de tais estudiosos ganha mais notoriedade quando observamos o ciclo das políticas públicas, como conceituado por outros autores como Viana (1996), Frey (2000) e Souza (2006). Para estes, todas as propostas de ação (políticas públicas) deveriam respeitar o ciclo de definição de uma agenda política, que é constituído, sequencialmente, pela percepção e/ou diagnóstico do problema, elaboração de programas, implementação das políticas, avaliação e eventuais correções. Ressalta-se, portanto, a partir das teorias conceituais das políticas públicas a necessidade em cumprir as etapas de diagnóstico e planejamento de uma determinada ação e sua aplicabilidade, antes de implantar efetivamente o plano de ação. Contudo, para Santos, Costa e Silva (2012), essa etapa fora visivelmente ignorada, decorrente da situação emergencial vivida pela proximidade do evento.

Ao observar, inclusive, que uns dos principais objetivos e direcionamentos do novo texto do programa Bolsa-Atleta, por meio da categoria Bolsa Pódio, é o de beneficiar atletas de modalidades olímpicas/paralímpicas individuais - que estejam ranqueados entre os 20 melhores do mundo - é possível inferir que o programa não foi criado, em sua totalidade, com o objetivo de estimular a criação, formação e/ou desenvolvimento de novos atletas, mas assegurar a manutenção dos atletas que já se encontram no topo de suas carreiras esportivas.

Portanto, ao estabelecer como função do programa Bolsa-Atleta a missão de estimular o desenvolvimento do esporte brasileiro a partir da base da pirâmide esportiva - como está mencionado no documento de Inteiro Teor, na justificativa da proposta elaborada pela Comissão de Educação, Cultura e Desporto da Câmara dos Deputados (BRASIL, 2001) -, fica exposta a fragilidade e imediatismo do programa e nos desperta a preocupação quanto à eficácia e efetividade de sua ação.

\section{Considerações finais}

De modo a respondermos nosso objetivo de pesquisa inicial e identificarmos qual o alcance do programa Bolsa-Atleta na formação de atletas do handebol brasileiro, foi possível identificar que 242 atletas integraram as seleções de base no período. Dentre eles, 181 (75\%) foram beneficiados por algum tipo de bolsa - o que corresponde a $22 \%$ de todos os beneficiários do programa Bolsa-Atleta (até dezembro de 2015) - e menos de 5\% foram beneficiados por bolsas das categorias de base (Bolsa Base e Bolsa Estudantil).

A partir desses dados, foi possível inferir que o programa Bolsa-Atleta não apresentou escala progressiva de beneficiamento ao handebol brasileiro, colocando em dúvida a perenidade do programa quanto à abrangência das categorias de formação. Os dados sugerem que o programa não priorizou seu investimento nos atletas de base da modalidade, colocando os objetivos das bolsas Base e Estudantil em situação de desconfiança. Pelo menos na modalidade handebol, o que se observou foi a fragilidade em garantir que o programa Bolsa-Atleta desempenhe um papel que fomente a formação, detecção e desenvolvimento de novos talentos. Essa consideração se dá devido aos elementos anteriormente expostos, em que, apesar de termos identificado que $75 \%$ dos integrantes das seleções de base tenham sido beneficiários do programa, menos de $5 \%$ desses atletas foram contemplados pelas categorias de base.

Os dados nos levam a questionar a efetividade do programa quanto ao alcance dos objetivos propostos - assegurar o desenvolvimento de novos talentos esportivos. A partir das informações supracitadas, evidenciamos a falta de investimento ou priorização das categorias de base da modalidade. Não obstante a priorização dos atletas no topo da modalidade, os dados nos permitem reforçar as características de uma ação de caráter imediatista, que prioriza o investimento nos atletas que já possuem potencial olímpico, em detrimento de um planejamento de longo prazo que possibilite a identificação e formação de novos atletas. Tal assertiva é visivelmente ilustrada quando observadas as estatísticas do programa no período abordado por essa pesquisa, que evidenciam que, pelo menos na modalidade em questão, não há 
evidências, a partir do programa Bolsa-Atleta, de um foco visando à ampliação da base da pirâmide esportiva.

Por fim, destacamos algumas limitações desse estudo devido ao fato de tratarmos, restritamente, de fontes documentais. Sugere-se, portanto, a realização de outros estudos de natureza investigativa, que tratem com maior profundidade e por meio de outros instrumentos de pesquisa - como entrevistas e/ou questionários - as percepções dos próprios atletas, técnicos e gestores acerca dessas políticas. Consideramos, inclusive, indispensável identificar métodos de avaliação dessas políticas, para que sejam desenvolvidos estudos que apontem, se necessárias, as modificações e correções oportunas para a melhor aplicação dessas políticas.

\title{
PUBLIC POLICIES FOR SPORT: BOLSA-ATLETA PROGRAM AND ITS COVER- AGE ON YOUTH HANDBALL PLAYERS IN BRAZIL
}

\begin{abstract}
This study focused on identifying the coverage of Bolsa-Atleta program in the formation of the Brazilian handball athletes from 2008 to 2014. This is a documental research with theoretical approach in Public Policy that used official sources of the Government, supported by the Programa Inteligência Esportiva of UFPR/Ministério dos Esportes and the lists of the covered athletes in the Bolsa-Atleta Program, released on the website of the Ministerio dos Esportes and properly published in the Official Gazette. It was concluded that there is prioritized investment in categories with highest value; Bolsa-Atleta program does not guarantee investment in the training of athletes in handball, because the categories Base and Estudantil did not reach $5 \%$ of the athletes of that modality.
\end{abstract}

Keywords: Handball. Bolsa-Atleta. Public Policy. Sport.

\section{POLÍTICAS PÚBLICAS PARA EL DEPORTE: EL PROGRAMA BOLSA-ATLETA Y SU COBERTURA SOBRE LA BASE DE BALONMANO EN BRASIL}

\begin{abstract}
Resumen
El objetivo de este estudio se centró en identificar el alcance del programa Bolsa-Atleta en la formación de los atletas de balonmano de Brasil entre 2008 y 2014. Esta investigación, de carácter documental y enfoque teórico sobre las Políticas Públicas, utiliza fuentes oficiales del Gobierno, con el apoyo del Programa de Inteligencia Deportiva de la Universidade Federal do Paraná (UFPR)/ Ministerio de Deportes y las listas de los que fueron incluidos en el Programa Bolsa-Atleta, divulgado en la página web del Ministerio de Deporte y debidamente publicado en el Diario Oficial del País. Se concluyó que existe una inversión prioritaria en las categorías de becas de mayor valor; el programa Bolsa-Atleta no garantiza la inversión en la formación de los atletas del balonmano, ya que las categorías de beca Base y Estudiante no alcanzó el 5\% de los atletas de esa modalidad deportiva.
\end{abstract}

Palabras-clave: Balonmano. Bolsa-Atleta. Política Pública. Deporte.

\section{Referências}

BARBANTI, V. J. Teoria e Prática do Treinamento Desportivo. 2. ed. São Paulo: Editora Edgard Blucher. 1979.

BOHME, M. T. S. O tema talento esportivo na ciência do esporte. Revista Brasileira de Ciência e Movimento, São Paulo, v. 15, n.1, p. 119-126, 2007. 
BOHME, M. T. S. Comparação Internacional das Políticas para o Esporte de Alto Rendimento (SPLISS) - A Participação do Brasil. Simpósio Internacional sobre Políticas para o Esporte de Alto Rendimento no Contexto Internacional. Universidade de São Paulo. São Paulo, 2013. Disponível em: <http://citrus.uspnet.usp.br/lateca/web/index.php/pt/eventos/sipear2013>. Acesso em: $01 \mathrm{dez}$. 2014.

BRASIL. Câmara Dos Deputados. Diário da Câmara dos Deputados. Brasília, DF, 30 de março de 2001, vol. 1, n. 41, 674 p. 2001.

BRASIL. Lei $\mathbf{n}^{\mathbf{0}}$ 10.891, de 09 de julho de 2004. Institui o Bolsa-Atleta. Disponível em:< http://www.planalto.gov.br/ccivil_03/_ato2004-2006/2004/lei/110.891.htm>. Acesso em: 01 dez. 2014.

Lei 12.395, de 16 de março de 2011. Altera as Leis $\mathrm{n}^{\mathrm{os}} 9.615$, de 24 de março de 1998, que institui normas gerais sobre desporto, e 10.891, de 9 de julho de 2004, que institui a Bolsa-Atleta; cria os Programas Atleta Pódio e Cidade Esportiva; revoga a Lei no 6.354 , de 2 de setembro de 1976; e dá outras providências.Disponível em:< http://www.planalto.gov.br/ccivil_03/_ato2011-2014/2011/lei/112395.htm>. Acesso em: 01 dez. 2014.

CAMARGO, P. R. DE. O desenvolvimento do handebol brasileiro a partir das políticas públicas do Governo Federal: da iniciação ao alto rendimento. Dissertação (Mestrado em Educação Física) - Universidade Federal do Paraná. Curitiba, PR, 2016.

CORRÊA, A. J.; SILVA, M. M.; MEZZADRI, F. M.; CAVICHIOLLI, F. R. Financiamento do esporte olímpico de verão brasileiro: mapeamento inicial do programa "bolsa-atleta" (2005-2011). Pensar a Prática, Goiânia, v. 17, n. 4, out./dez. 2014.

CORRÊA, A. J. A autonomia da vontade das confederações esportivas no programa bolsa-atleta: análise da legislação e suas relações. Dissertação (Mestrado em Educação Física) Universidade Federal do Paraná. Curitiba, PR, 2016.

DE BOSSCHER, V., et al. Sports Policy factors Leading to International Sporting Success. Oxford: Meyer \& Meyer Sport (UK) Ltd., 2007.

DE BOSSCHER, V., et al. Explaining international sporting success: An international comparison of elite sport systems and policies in six countries. Sport Management Review, Sydney, v.12, p.113-36, 2009.

DE BOSSCHER, V., et al. Developing a Method for Comparing the Elite Sport Systems and Policies of Nations: A Mixed Research Methods Approach. Journal of Sport Management, Champaign, p. 567-600, 2010.

DE BOSSCHER, Veerle, et al. Competitiveness of Nations in Elite Sport: An international comparison of the Sport Policy factors Leading to International Sporting Success (2011-2012). SPLISS II. Research Proposal, Vrije Universiteit Brussel, [2013]. Disponível em: < http://www.vub.ac.be/SBMA/spliss >. Acesso em: 20 jun. 2016. 
FREY. K. Políticas públicas: Um Debate Conceitual e Reflexões Referentes à Prática da Análise de Políticas Públicas no Brasil. Planejamento e Políticas Públicas, n 21, 2000.

GUIMARÃES, A. S. A Bolsa-Atleta eleva o desempenho de seus beneficiários? Análise do período 2005-2008. Consultoria do Senado Federal. Centro de Estudos. Brasília, 2009.

HOUlihAN, B.; GREEN, M. Comparative Elite Sport Development: Systems, Structures and Public Policy. Oxford: Elsevier, 2008.

HOULIHAN, B.; ZHENG, J. The Olympic and Elite Sport Policy: Where will it all end? International Journal of History of Sport, n 30, p. 338-355, 2013.

LAKATOS, E. M.; MARCONI, M. de A. Fundamentos de metodologia cientifica. 3. ed. rev. e ampl. São Paulo: Atlas, 1991. 270p.

MALINA, R. M; BOUCHARD, C. Growth, maturation, and physical activity. Champaign, II: Human Kinetics Books, 1991.

MATTA, M. de O.; GRECO, P. J. O Processo de Ensino-Aprendizagem-Treinamento da Técnica Esportiva aplicada ao Futebol. Revista Mineira de Educação Física, Viçosa, v. 2, n. 4, , p. 34-50, 1996.

MAZZEI, L, C,; SANTOS, J. M, C, M.; BASTOS, F. da C.; BÖHME, M. T. S. Projetos para tornar o Brasil uma potência esportiva: um estudo preliminar. In: Simpósio Internacional de Gestão de Projetos, 1, 2012, São Paulo. Anais..., São Paulo: UNINOVE, 2012, v. 1, p. 1-23.

REIS, R. E.; SILVA, M. M. ; FIGUERÔA; K. M.; ALMEIDA, B. S. de; MEZZADRI, F. M. Dez anos do programa federal "Bolsa Atleta": uma descrição das modalidades Paralímpicas (2005-2014). Pensar en Movimiento, San José, v. 13, n. 2, p. 1-18, dez. 2015.

SHILBURY, D.; SOTIRIADOU, K.; GREEN, B. C. Sport Development Systems, Policies and Pathways: An Introduction to the Special Issue. Sport Management Review, Sidney, n. 11, p. 217-223, 2008.

SANTOS, S. C. dos; COSTA, L. P.; SILVA, C. H. V. da. Rio 2016 e o Plano Brasil Medalhas: Seremos uma Potência Olímpica? PODIUM: Sport, Leisure and Tourism Review. São Paulo, v. 1, n. 1, p. 66-87, jan./jun. 2012. Disponível em:< http://www.podiumreview.org.br/ojs/index.php/rgesporte/article/view/17/pdf>. Acesso em: 19 nov. 2014

SILVA, M. M. e; MEZZADRI, F. M.; SANTOS, N.; CAMARGO, P. R. de; FIGUERÔA, K. M. A configuração do ordenamento jurídico relativo ao Financiamento do governo brasileiro ao esporte de rendimento: Uma análise a partir da teoria dos jogos de Norbert Elias. Lúdica Pedagógica, n. 21, v. 1, p. 77-89, 2015.

SOUZA, C. Políticas Públicas: Uma Revisão da Literatura. Sociologias, Porto Alegre,, n 16, 2006. 
TEIXEIRA, M. R.; MATIAS, W. B.; MASCARENHAS, Fo. O Financiamento do Esporte Olímpico no Brasil: Uma análise do Ciclo de Londres (2009-2012). Revista Ciencias Sociales, Inquique, n. 31, p.86-110, jul./dez. 2013.

VIANA, A. L. Abordagens metodológicas em políticas públicas. Revista de Administração Pública, Rio de Janeiro, Cidade do México, v. 30, n. 2, p. 5-43, 1996.

Recebido em: 23/02/2016

Revisado em: 08/06/2016

Aprovado em: 11/07/2016

Endereço para correspondência:

philipe_camargo@ hotmail.com

Philipe Rocha de Camargo

Universidade Federal do Paraná, Pós-graduação em Educação Física Stricto Sensu

Rua Coração de Maria, 92

Campus Jardim Botânico

80210-132 - Curitiba, PR - Brasil 